\title{
FORMAÇÃO CONTINUADA ON-LINE PARA PROFESSORES MATICE
}

\author{
Continued formation online for matice professors
}

\author{
Patrícia Lupion Torres ${ }^{a}$, Marilda Aparecida Behrens ${ }^{b}$, \\ Ricardo Tescarolo ${ }^{c}$, Elizete L. M. Matos ${ }^{\mathrm{d}}$ \\ a Doutora em Engenharia da Produção pela UFSC; Professora Titular da PUCPR, Curitiba, \\ PR - Brasil, e-mail: patorres@terra.com.br \\ ${ }^{b}$ Doutora em Educação pela PUCSP. Professora titular da PUCPR. Pesquisadora do \\ CNPq, Curitiba, PR - Brasil, e-mail: marilda.aparecida@pucpr.br \\ c Doutor em Educação pela USP. Professor do Programa de Pós-Graduação da PUCPR, \\ Curitiba, PR - Brasil, e-mail: rtescarolo@pucpr.br \\ d Doutora em Engenharia da Produção pela UFSC; Professora Titular da PUCPR, Curitiba, \\ PR - Brasil, e-mail: elizete.matos@pucpr.br
}

\section{Resumo}

Este artigo apresenta uma experiência vivenciada na formação continuada on-line com professores universitários envolvidos no programa MATICE (Metodologias de Aprendizagem via Tecnologias de Informação e Comunicação Educacionais). A proposta foi desenvolvida pela Diretoria de Educação a Distância da PUCPR em conjunto com o grupo de pesquisa PEFOP (Paradigmas Educacionais e Formação de Professores). Centrou-se o objetivo desta proposta na preparação de docentes para a utilização pedagógica de tecnologias da informação e comunicação na proposição de disciplinas on-line. O professor participante da formação continuada foi desafiado a tornar-se um agente mediador em busca de processos de ensino que abordem a aprendizagem em seus aspectos de elaboração pessoal e coletiva. Com essa visão, propiciou-se aos professores o desenvolvimento de capacidades para poder selecionar melhor a mídia disponível para cada situação de

Rev. Diálogo Educ., Curitiba, v. 8, n. 24, p. 433-444, maio/ago. 2008 
aprendizagem. A experiência vivenciada junto a estes professores permitiu aos pesquisadores levantar algumas contribuições relevantes que se apresentam neste artigo a partir da reflexão dos profissionais envolvidos no processo de formação continuada.

Palavras-chave: Formação continuada de professores; TIC; Universidade virtual; Educação a distância.

\begin{abstract}
This article presents a lived experience in the continued formation on line with university professors in the program MATICE (Information and Communication Technologies in Education). The proposal was developed by the Direction of the Distance Education of PUCPR with the group of research PEFOP (Educational Paradigms and Formation of Professors). The objective of this proposal is the preparation of professors for the pedagogical use of information and communication technologies in online disciplines. The participant professor of the continued formation was defied to become a mediator in search of education processes that approach the learning in its aspects of personal and collective elaboration. With this vision, it was propitiated the professors the development of capacities to be able to better select the available media for each situation of learning. The experience lived with these professors allowed the researchers to reach some excellent contributions that is present in this article from the reflection of the involved professionals in the process of continued formation.
\end{abstract}

Keywords: Continued formation of professors; ICT; Virtual university; Distance education.

A humanidade, no século XXI, tem sido desafiada a enfrentar um tempo de grandes transformações. Estas mudanças envolvem um acelerado processo de globalização, a mudança paradigmática da ciência, a exigência de uma educação que valorize a aprendizagem por toda vida, a convivência com o acúmulo de informações, o enfrentamento da hegemonia crescente da ciência e da tecnologia, entre outros.

$\mathrm{O}$ avanço da sociedade inclui as oportunidades de acesso à informação que vêm sendo incrementadas pelo uso das novas tecnologias de

Rev. Diálogo Educ., Curitiba, v. 8, n. 24, p. 433-444, maio/ago. 2008 
comunicação, em especial, pelo uso da rede informatizada. Assim, milhões de pessoas têm acessado as redes de informação, com ênfase na utilização da comunicação via internet. Este movimento não pode ser ignorado pelas instituições educacionais. Sem dúvida, a introdução maciça das redes digitalizadas em todos os níveis da sociedade leva a repensar os processos de ensinar e de aprender.

\section{Formação continuada de professores: o desafio das instituições de educação superior}

Os professores e alunos precisam estar preparados para o enfrentamento das TIC (Tecnologias da Informação e da Comunicação) e as Instituições de Educação Superior podem criar espaços privilegiados para oferecer esta formação. Os processos de qualificação, sejam de alunos ou de professores, podem e devem se apropriar das TIC, como afirma Almeida (2003, p. 114):

Há que se empregar nas ações de formação todos os recursos disponíveis, inclusive as TICs, tendo em vista a criação de comunidades colaborativas que propiciem aos educadores a tecitura de suas próprias redes de interrelações humanas e de conhecimentos, cuja trama indica a construção de uma sociedade solidária e mais humana. O fator primordial para criação de comunidades e culturas colaborativas de aprendizagem é a qualidade da interação, quer presencial, quer a distância, cujas articulações podem ser viabilizadas a partir da formação continuada e em serviço do educador.

A recomendação da utilização das TICs para a formação continuada de professores vem aliada à necessidade da formação pedagógica para o uso adequado destes recursos. Cabe enfatizar que as escolas já assumiram a utilização da rede informatizada para os serviços administrativos. A disponibilidade dos laboratórios de informática implantados nas escolas, em todos os níveis, em geral, tem servido para acesso a jogos, a comunicação pela Internet e para recreação. O grande salto qualitativo que se espera do professor é a utilização pedagógica dos recursos de mídias dentro das disciplinas, ou seja, a opção pelo laboratório para ensinar e para aprender os conhecimentos específicos das disciplinas.

Com esta visão, a formação contínua do professor precisa incorporar possibilidades de reorganizar a prática pedagógica incluindo as novas tecnologias da informação e da comunicação no sentido de ampliar os recursos de aprendizagem. Nesse sentido, Almeida (2003, p. 115) reforça esta proposta quando alerta:

Rev. Diálogo Educ., Curitiba, v. 8, n. 24, p. 433-444, maio/ago. 2008 
Nessa formação, cujo eixo articula a realidade da escola com o domínio dos recursos tecnológicos e a prática profissional com as TICs (ALMEIDA, 2003), o educador terá a oportunidade de identificar e analisar as problemáticas envolvidas em sua atuação na sua escola, no sistema educacional e na sociedade.

Os processos educacionais precisam incorporar as novas tecnologias ligadas às redes informacionais. A educação superior já começa a acolher os alunos que nasceram na sociedade do conhecimento. Os professores devem acompanhar este movimento e contemplar em suas práticas pedagógicas recursos compatíveis com as exigências desta sociedade.

Em tempos de transformações tão profundas e abrangentes, principalmente, na concepção de conhecimento e visão de mundo, a atualização desses professores assume importância estratégica. De fato, a eficácia do uso de tecnologias educacionais na Universidade decorre principalmente do resultado da qualidade da agência formadora. No contexto mais amplo da função social de formação continuada, as questões da profissionalização dos professores encontram sua significação mais clara. As propostas de intervenção mais relevantes acolhem a necessidade de compreensão e transformação da realidade.

O avanço no processo de formação do professor, seja presencial ou on-line, implica em superar as propostas de modelar e de conformar, ou seja, oferecer propostas pedagógicas que superem a visão de reducionista de treinamento. A formação continuada on-line precisa buscar caminhos que levem à reflexão na e pela ação (NÓVOA, 1992) para qualificar os profissionais e convencêlos da necessidade de modificar e transformar seu papel docente (BEHRENS, 2006). Os ambientes virtuais de aprendizagem propiciam novas estratégias que precisam estar presentes na proposta de formação continuada de professores. É inegável que as universidades têm apresentado crescente virtualização, assim, a utilização dos ambientes virtuais pode integrar múltiplas mídias e recursos gerando novos procedimentos para formar, ensinar e para aprender.

O núcleo central da proposta de formação pedagógica fica focalizado na superação da reprodução para a produção do conhecimento. Alertou-se para a necessidade de ultrapassar propostas pedagógicas focalizadas na repetição e na memorização. As perspectivas de buscar um novo paradigma, ou seja, o paradigma da complexidade na sociedade do conhecimento leva a repensar a prática pedagógica proposta no ensino universitário (BEHRENS, 2005). Frente à nova realidade, o professor foi desafiado a ultrapassar seu papel autoritário, de dono da verdade, para se tornar um investigador, articulador e pesquisador crítico e reflexivo. Neste contexto, além de um profissional

Rev. Diálogo Educ., Curitiba, v. 8, n. 24, p. 433-444, maio/ago. 2008 
competente, o docente precisa tornar-se um cidadão autônomo e criativo, que saiba solucionar problemas e manter constante iniciativa para questionar e transformar a sociedade.

Os novos processos de qualificação docente, em especial os que utilizam ambientes virtuais, precisam atender a estes novos desafios do paradigma inovador. Nesse sentido, os docentes devem ser provocados para eleger metodologias que proponham problematizações a partir da realidade do aluno, que provoquem questionamentos e que ofereçam aos estudantes aprendizagem com visão complexa. O paradigma da complexidade implica no processo formativo no qual a ação crítica do formador passa a ser decisiva.

\section{A formação continuada dos professores proposta pela Diretoria de Educação a Distância e pelo PEFOP na PUCPR}

Designa-se por formação continuada aquela derivada da ocupação profissional empreendida após o período da graduação que licencia uma pessoa como profissional do ensino - portanto com intenção de aperfeiçoamento mais do que de aquisição de base. Essa concepção corresponde àquela da UNESCO, ao considerá-la como a aquisição de competências intimamente associadas ao campo profissional. A formação continuada dos profissionais em serviço integra o conjunto de "todos os processos de construção cultural de uma população ao longo de toda a vida, e supõe a atualização científica, psicopedagógica e cultural, complementar" (IMBERNÓN, 1994, p. 13).

A formação continuada dos professores e sua prática pedagógica proposta pela Diretoria de Educação a Distância e pelos professores do Programa de Pós-Graduação em Educação da PUCPR, do grupo PEFOP - Paradigmas Educacionais e Formação Professores - buscou construir uma proposta que fosse além do simples uso de novas tecnologias de informação e comunicação. Assim, nesta proposta, os docentes foram desafiados a identificar, analisar e operacionalizar sua ação pedagógica com uma nova visão paradigmática. Neste processo, os docentes precisam avaliar as variáveis encontradas no interior do sistema escola, na forma como elas se apresentam na realidade cotidiana e no entorno do sistema, ou seja, no contexto político, social, econômico e cultural (FALCÃO FILHO, 1997, p. 181-191).

Com esta visão, a prática docente precisa considerar o contexto, pois o professor como agente formador e investigador da natureza humana não pode ser apenas um profissional que, caminhando com os olhos fixos nas estrelas, cai em um buraco. No entanto, estar "no buraco sem nunca ter saído é muito pior. É o que aconteceria se permanecesse, em sentido positivista, ligado aos fatos meramente enquanto fatos, aos fenômenos puros e simples [...]" (IMODA, 1996, p. 53-54).

Rev. Diálogo Educ., Curitiba, v. 8, n. 24, p. 433-444, maio/ago. 2008 
Essa constatação implica numa visão mais complexa da formação pedagógica, em especial, propondo um projeto de formação continuada que priorize o manejo mais amplo dos saberes pedagógicos. Estes saberes precisam ser alimentados pelos questionamentos constantes do conhecimento, que provocam posicionamentos críticos que podem se tornar convergentes ou divergentes. Assim, permite a produção do conhecimento como aliança entre a elaboração pessoal e construção coletiva. A busca pelo aprofundamento dos saberes implica em propor a aprendizagem em suas implicações emocionais, afetivas e relacionais. Isso impõe à instituição de ensino superior o compromisso de propiciar aos seus professores o desenvolvimento da capacidade de selecionar as melhores metodologias e, por conseqüência, a inclusão dos recursos disponíveis para cada uma das situações de ensino-aprendizagem.

Destaca-se que, ao se insistir aqui na importância da formação continuada dos professores, em verdade se está insistindo principalmente na necessidade da educação contínua de uma pessoa ao longo da vida. Para tanto, deve ser leitora e autora de uma visão de mundo. Afinal, a visão dos professores, não pode se limitar a fixar o olhar no dedo que aponta, mas estender sua perspectiva para aquilo que o dedo aponta: a constelação das novas possibilidades nascidas no interior de uma extraordinária metamorfose criadora de vida e de encantamento, mas que se alimenta de enfrentamentos. Para tanto, impõe-se a articulação de novos conhecimentos, com novos objetivos e formas de aprendizagem e de mediação, mediante o desenvolvimento de uma cartografia de relevâncias que funcione como um radar capaz de perscrutar uma realidade mutante.

A proposta de formação continuada da Diretoria de Educação a Distância e do grupo de pesquisadores do PEFOP focalizou o uso de novas tecnologias de informação e comunicação e subsidiou os docentes com os pressupostos basilares que assegurassem as condições necessárias para o exercício crítico da ação formativa. Esta formação implicou em oferecer processos que sustentassem a incorporação, o desenvolvimento e a apropriação de conhecimentos significativos. Neste contexto, buscou-se assegurar ao professor:

- base teórica que evite transformá-lo em um técnico treinado exclusivamente no enfrentamento de uma rotina mecânica e burocrática, baseada na transmissão de informações;

- ação pedagógica que se torne eficaz a partir da criação de condições para que se realize uma análise crítica da realidade, o que supõe a superação de um currículo fragmentado, que separa e entende o conhecimento como um encadeamento de informações;

- desenvolvimento da capacidade de pesquisa como meio de produção de conhecimento;

Rev. Diálogo Educ., Curitiba, v. 8, n. 24, p. 433-444, maio/ago. 2008 
- continuidade do processo de formação continuada em serviço, que não dispensa, antes reforça, um programa pessoal permanente de estudos.

Para fazer frente a estas exigências, o grupo de pesquisadores optou por oferecer aos professores procedimentos diversificados e sistemáticos, organicamente estruturados, possibilitando o aperfeiçoamento e a atualização permanente dos docentes que atuam na Universidade.

\section{O EUREKA e o MATICE: ferramentas para a virtualização da PUCPR}

A PUCPR iniciou os investimentos na educação on-line em 1995, desenvolvendo pesquisas para criação do ambiente virtual de aprendizagem denominado EUREKA. Este ambiente oferece interatividade, que gera diferentes formas de conexão nas salas virtuais. Os professores se tornam mediadores nestas salas, pois são responsáveis diretos pelo sucesso do processo. A tecnologia em si não sustenta $\mathrm{o}$ aprendizado, mas a participação ativa do professor garante os aspectos de colaboração/cooperação, de responsabilidade e de motivação pela atividade em desenvolvimento.

O EUREKA tem permitido o desenvolvimento de processos que propiciem a interatividade com eficiência e rapidez, possibilitando a navegação fácil, a disponibilização de conteúdos, do planejamento e do cronograma de atividades. Além desses recursos, oportuniza a utilização de correio eletrônico, de fóruns virtuais, de acesso à biblioteca e de links para atividades de pesquisas.

As características do EUREKA, acima apontadas, dependem da utilização do professor, que deve atuar como um mediador que propõe o processo ensino-aprendizagem. O sucesso da aprendizagem depende de uma aproximação entre a teoria e prática.

A utilização intensiva do EUREKA por alunos e professores possibilitou que, em 2002, fosse proposta pela Pró-Reitoria Acadêmica, da PUCPR, o Sistema MATICE - Metodologias de Aprendizagem via Tecnologias de Informação e Comunicação Educacionais. Os pesquisadores do PEFOP e a equipe técnica da Diretoria de Educação a Distância envolvidas no Sistema MATICE passou a oferecer acompanhamento e monitoramento das ações pedagógicas no EUREKA - Ambiente Virtual de Aprendizagem da PUCPR para os professores e os alunos participantes.

Em 2003, iniciou-se uma experiência-piloto com algumas disciplinas ofertadas dentro do ambiente on-line. Os resultados das pesquisas realizadas nas turmas implantadas foram significativos e determinantes para que, em 2004, os

Rev. Diálogo Educ., Curitiba, v. 8, n. 24, p. 433-444, maio/ago. 2008 
alunos que não lograram aprovação em alguma disciplina presencial, ou seja, os alunos dependentes, pudessem optar por realizá-las de novo na modalidade semipresencial (TORRES, 2004, p. 297).

O MATICE, em 2006, foi definitivamente consolidado. De acordo com dados da Diretoria de EAD da Pró-Reitoria Comunitária e de Extensão PUCPR, havia em 2006: 1017 professores atuando em 1279 turmas on-line, com 4719 alunos dependentes. E, em 2007, havia 1310 turmas de dependência on-line em funcionamento, atendendo 5262 alunos, o que envolveu um total de 1209 professores.

A fim de corresponder e acompanhar o processo de virtualização da PUCPR, a diretoria de EAD propôs, em 2007, em conjunto com o grupo PEFOP, um processo de formação continuada para professores que atuavam em disciplinas on-line na PUCPR, no Sistema MATICE, focalizado num redimensionamento de suas práticas pedagógicas.

A provocação para elaborar uma nova abordagem na prática docente se fez acompanhar de base teórico-prática para potencializar o uso de Tecnologias de Informação e Comunicação na educação virtual de uma forma crítica, criativa, dialógica, interativa e que corresponda aos pressupostos do paradigma da complexidade.

Assim, foi proposto aos docentes do MATICE um primeiro módulo on-line, no qual puderam vivenciar um processo de reavaliação de suas práticas e elaboraram novas propostas de ação docente, em especial, nas atividades realizadas no ambiente virtual.

Essa formação pedagógica teve a intenção de preparar o professor para uma utilização criteriosa do computador como ferramenta para ensinar e aprender. Serviu, também, para alertar os docentes de que os recursos tecnológicos podem e devem ser utilizados com criticidade e como recurso auxiliar na difusão, transmissão e produção de conhecimento.

\section{Os avanços e desafios ao longo da pesquisa na formação continuada on-line}

Esta pesquisa envolveu a temática da formação pedagógica dos professores, partindo da problematização, da reflexão e da análise da prática pedagógica, do ensino e da aprendizagem com utilização de tecnologias educacionais, bem como permitiu a publicação deste artigo, que tem como objeto o relato da formação para docência no ensino que envolva ambientes virtuais numa abordagem inovadora.

Os procedimentos de investigação utilizados foram: revisão de literatura; proposição do designer do ambiente virtual, desenvolvimento, acompanhamento, implantação e avaliação do curso de formação continuada de professores que atuam

Rev. Diálogo Educ., Curitiba, v. 8, n. 24, p. 433-444, maio/ago. 2008 
no Sistema MATICE. Os dados de pesquisa foram coletados a partir do desenvolvimento, validação e aplicação de questionário junto aos professores envolvidos e das contribuições colhidas nos fóruns do ambiente virtual. Esses dados deram origem à análise e à discussão dos dados obtidos durante o curso.

A revisão da literatura forneceu a base teórica para a formação pedagógica que focalizou a mudança paradigmática da ciência, sua influência da Educação e os reflexos na prática pedagógica. Tomou como referência a necessidade de superação do paradigma conservador e a busca de um paradigma inovador que atenda à produção do conhecimento num processo reflexivo, crítico e transformador. A superação da abordagem tradicional torna-se emblemática neste processo formativo, pois a maioria dos programas de formação a distância repousa sobre pouca interatividade e fundamenta-se na prática pedagógica conservadora. Nesse sentido, Freire (1998, p. 81) alerta: "ensinar não é simples transmissão de conhecimento em torno do objeto ou do conteúdo". Assim, também os processos de ensinar e de aprender na educação distância devem atender a um novo paradigma, ou seja, superar aprendizagem que leva à reprodução para buscar a produção do conhecimento.

A pesquisa teve como foco central a investigação sobre a possível reconstrução da ação docente desencadeada no curso on-line de formação pedagógica para professores que atuam no MATICE. Nesse processo conjunto, os professores-alunos aliam-se aos pesquisadores para refletir e discutir sobre os paradigmas inovadores na formação continuada dos docentes e as novas metodologias na Educação Superior. Conforme alerta Nóvoa (1992, p. 25), “A formação não se constrói por acumulação (de cursos, de conhecimento ou de técnicas), mas sim por um trabalho de reflexividade crítica sobre as práticas e de (re)construção permanente de uma identidade pessoal". E acrescenta: "Por isso, é tão importante investir na pessoa e dar um estatuto ao saber da experiência".

A pesquisa foi desenvolvida pelo grupo do PEFOP com quatro pesquisadores, os 8 profissionais da equipe técnica da Diretoria de Educação a Distância e os 37 professores-alunos (dos 42 docentes envolvidos inicialmente no processo) do curso de formação continuada de vários cursos, centros e de vários campi da PUCPR. Os dados de pesquisa foram determinados por uma amostra não probabilística intencional. Assim, a coleta refere-se a uma população composta por 37 professores-alunos que concluíram a formação continuada, dos 42 docentes que se propuseram a acompanhar o processo.

Para a coleta de dados, optou-se como um dos instrumentos de pesquisa pelo questionário que foi enviado aos docentes por meio do Ambiente Virtual de Aprendizagem EUREKA, os quais foram tratados estatisticamente. A avaliação quanti-qualitativa serviu-se de dados colhidos no questionário, no acompanhamento das turmas e pelas contribuições dos professores-alunos via fórum em ambiente virtual.

Rev. Diálogo Educ., Curitiba, v. 8, n. 24, p. 433-444, maio/ago. 2008 
A caminhada na pesquisa permitiu que os participantes refletissem com criticidade sobre a docência universitária on-line, em especial, a aprendizagem e as metodologias de ensino que viessem a atender ao paradigma da complexidade. Os encontros virtuais propiciaram a construção de referenciais que alicerçam uma prática pedagógica que supere os processos de reprodução de conhecimento, de uma forma crítica, dialógica, reflexiva, a fim de garantir a produção do conhecimento dos professores-alunos. Para tanto, os professores-alunos, por meio de discussões on-line, via Chat e via Fórum, refletiram sobre suas práticas pedagógicas. A formação on-line para docentes MATICE levou os professoresalunos envolvidos na pesquisa a refletirem sobre a necessidade de propor um processo de ação pedagógica inovador, que exige novos procedimentos de ensino e de organização didática.

Os diversos momentos de discussão e construção coletiva sobre os processos de aprendizagem e as metodologias de ensino auxiliaram os professoresalunos na opção pelo novo paradigma na prática docente. Cabe ressaltar que ao propor o paradigma da complexidade, buscou-se atender aos pressupostos norteadores: a produção do conhecimento, a transformação da realidade, a visão de todo, de rede e de teia. A reflexão e a discussão conjunta buscaram provocar a preparação dos professores-alunos para atuar na docência on-line de maneira crítica, reflexiva e transformadora.

\section{CONSIDERAÇÕES FINAIS}

O envolvimento dos professores-alunos no processo de desenvolvimento profissional possibilitou a reflexão e a elaboração de uma prática pedagógica num paradigma da complexidade. O acompanhamento dos pesquisadores se fez presente ao longo da pesquisa e por meio da investigação das manifestações dos docentes em diferentes momentos foi possível a elaboração de uma análise do processo.

As contribuições dos professores-alunos focalizaram a pertinência do curso e a possibilidade de realizá-lo de acordo com a administração de seu tempo, já que o ambiente virtual permite que o professor escolha quando e aonde vai realizar seus estudos e as atividades. Seria difícil oferecer um horário único de consenso a todos os envolvidos.

A proposição da formação continuada dos professores permitiu sua vivência no papel de aluno em ambiente on-line EUREKA. A proposta do grupo de pesquisadores foi de oferecer, na prática, a possibilidade de mostrar aos docentes como propor suas disciplinas num ambiente virtual de maneira crítica e reflexiva e que permita produzir conhecimento.

Rev. Diálogo Educ., Curitiba, v. 8, n. 24, p. 433-444, maio/ago. 2008 
O fato de participar da pesquisa mobilizou os docentes para a discussão sobre a concepção que norteava suas práticas e a reflexão sobre por que os professores universitários têm dificuldade de alterar a prática pedagógica junto aos seus alunos. Nas primeiras descobertas, foi possível constatar que não se tratava só da vontade para mudar, mas da necessidade de subsídios teóricos e de suporte pedagógico para avaliar como caracterizam suas práticas pedagógicas ao longo de suas vidas.

Vale ressaltar que a grande maioria dos professores universitários tem mantido na prática pedagógica uma abordagem tradicional, conservadora e cartesiana. O grupo de pesquisadores sabia que, num primeiro momento, a expectativa dos professores-alunos era a de encontrar receitas prontas para colocar na sua prática. Ao longo do processo, o professor percebeu que precisava refletir por que sua ação docente e que poderia projetar um paradigma conservador ou inovador em sua prática pedagógica. O desafio foi auxiliar os docentes no sentido de buscar novas possibilidades de construir uma docência universitária compatível com a Sociedade do Conhecimento.

\section{REFERÊNCIAS}

ALMEIDA. M. E. B. Tecnologias e gestão do conhecimento na escola. In: VIEIRA, A. T.; ALMEIDA, M. E. B.; ALONSO, M. Gestão educacional e tecnologia. São Paulo: Avercamp, 2003. p. 101-117.

BEHRENS, M. A. O paradigma emergente e a prática pedagógica. Petrópolis, RJ: Vozes, 2005.

Paradigma da complexidade: metodologia de projetos, contratos didáticos e portfólios. Petrópolis, RJ: Vozes, 2006.

FALCÃO FILHO, J. L. Formação e prática dos educadores antigos e novos paradigmas. In: PINTO. F. C. F.; FELDMANN G., SILVA R. C. (Org.). Administração escolar e política da educação. Piracicaba, SP: UNIMEP, 1997. p. 181-191.

FREIRE, P. Pedagogia da esperança: um reencontro com a pedagogia do oprimido. Rio de Janeiro: Paz e Terra, 1998.

IMBERNÓN, F. La formación del profesorad: papeles de pedagogía. Barcelona: Paidós,1994.

IMODA, F. Psicologia e mistério: o desenvolvimento humano. Tradução de Adalto Luiz Chitolina; Mathias J. A. Ham. São Paulo: Paulinas, 1996.

Rev. Diálogo Educ., Curitiba, v. 8, n. 24, p. 433-444, maio/ago. 2008 
NÓVOA, A. Os professores e sua formação. Lisboa: Dom Quixote, 1992.

TORRES, P. L. Laboratório on-line de aprendizagem: uma proposta crítica de aprendizagem colaborativa para educação. Tubarão: Unisul, 2004.

Recebido: 10/02/2008

Received: $02 / 10 / 2008$

Aprovado: 25/03/2008

Approved: 03/25/2008 